\title{
Kernos
}

Revue internationale et pluridisciplinaire de religion grecque antique

3 | 1990

Varia

\section{E.N. LANE, Corpus Cultus Iouis Sabazii, III,}

\section{Conclusions}

Fabio Mora

\section{OpenEdition \\ Journals}

\section{Édition électronique}

URL : http://journals.openedition.org/kernos/1032

DOI : 10.4000/kernos. 1032

ISSN : 2034-7871

\section{Éditeur}

Centre international d'étude de la religion grecque antique

Édition imprimée

Date de publication : 1 janvier 1990

ISSN : 0776-3824

\section{Référence électronique}

Fabio Mora, «E.N. LANE, Corpus Cultus louis Sabazii, III, Conclusions », Kernos [En ligne], 3 | 1990, mis en ligne le 16 juin 2011, consulté le 24 septembre 2020. URL : http://journals.openedition.org/kernos/ 1032 ; DOI : https://doi.org/10.4000/kernos. 1032 
Outre un aperçu géographique et historique de l'île, l'A. consacre un chapitre intitulé «Les mythes de Crète» aux dieux et aux héros locaux, aux mythes de la naissance de Zeus, de son union avec Europe, au royaume de Minos, à Talos, et à l'art minoen. Des monuments figurés, utilisés en abondance pour illustrer les mythes exposés dans ce chapitre, un grand nombre proviennent de Crète même et sont peu connus.

Parmi les renseignements pratiques destinés au voyageur, on consultera avec profit l'agenda des manifestations culturelles qui mentionne les fêtes religieuses chrétiennes et les "panigyria" locaux; les 26 circuits proposés comptent presque tous des sites religieux préhistoriques ou historiques.

\section{Éveline LOUCAS-DURIE}

E.N. LANE, Corpus Cultus Iovis Sabazii, III, Conclusions, Leiden, Brill, 1989, 68 p., 2 tableaux, index (Études préliminaires aux religions orientales dans l'Empire romain, 100).

Ce bref tome conclut le Corpus Cultus Iovis Sabazii, travail que se sont partagé le regretté professeur Vermaseren et l'A. à qui l'on doit le recueil des textes littéraires et des monuments autres que les mains (CCIS II). Il nous donne ici un clair aperçu de nos connaissances sur le culte, avec une grande prudence qui frise même l'hypercritique.

Dans le premier chapitre (1-10), il dessine l'histoire du culte avant l'Empire romain, pour souligner qu'au début du Ier siècle, le culte fleurissait aussi en dehors de l'Anatolie, surtout en Thrace et en Campanie : l'A., qui n'aborde pas le (faux) problème de l'étymologie du nom et de l'origine thrace ou phrygienne du dieu, est un peu trop prudent dans l'utilisation des premiers témoignages, mais donne une bonne présentation des moments principaux de l'histoire hellénistique du culte (surtout son introduction officielle à Pergame, les sociétés de Sabaziastes dans le monde égéen, le temple thrace dont Alexandre Polyhistor se fait le témoin). Il étudie ensuite (11-22) le problème des divinités identifiées à Sabazios ou vénérées avec lui, pour souligner l'équivalence très répandue entre Sabazios et Zeus, et la forte relation entre Sabazios et Mercure. Dans un troisième chapitre (23-37), dédié aux symboles et aux formes du culte, il nous semble un peu abuser des rapprochements, plutôt superficiels, avec le culte chrétien. Le quatrième chapitre (38-48) ne réalise qu'en partie les promesses d'un titre séduisant (The cult in the Roman empire : who worshipped Sabazius and $w h y)$ : quelques aperçus statistiques, que serait venu compléter heureusement un exposé plus substantiel. Bon exposé du problème des variantes orthographiques du nom divin. Le cinquième chapitre (49-60) est dominé par la volonté d'expliquer toutes les notices qui rapprochent Sabazios et Dionysos, par rapport à la maigre documentation épigraphique, d'une tradition purement littéraire basée sur le fameux passage 
de Démosthène : dans les termes radicaux qui servent à sa présentation, cette thèse ne nous convainc pas, même si nous reconnaissons le poids de certains arguments. Il faudra aussi tenir compte d'une interprétation dionysiaque des aspects mystiques du culte, interprétation qui, si elle n'est pas confirmée par les données épigraphiques (il s'agit d'une affinité typologique et non d'une réelle association cultuelle), ne se fonde pas non plus uniquement sur un malentendu : nous n'acceptons donc pas l'idée de l'A. qui pense avoir expliqué dans ce dernier chapitre "how a literary tradition can arise, flourish, and continue for centuries completely divorced from reality" (p. 60).

Ces quelques objections ponctuelles ne doivent pas faire oublier l'utilité d'une synthèse fondée sur une bonne connaissance de tous les témoignages du culte, synthèse dont l'absence se faisait sentir.

Fabio MORA

Maria ROCCH, Kadmos e Harmonia. Un matrimonio problematico, Roma, 'L'Erma' di Bretschneider, 1989, 144 p., 17 x $24 \mathrm{~cm}$. (Storia delle religioni, 6). ISBN : 88-7062-648-2.

Le mariage de Kadmos et d'Harmonie fait partie des événements fondateurs du cosmos; c'est ce que montre l'analyse très fine de $\mathrm{M}$. Rocchi dans ce petit ouvrage très stimulant. Conformément à la méthodologie de l'«École de Rome», le mythe est étudié pour lui-même et par lui-même, le sens se révélant de la confrontation des variantes que la tradition fournit en relation avec l'événement en question. Les éléments fondamentaux du récit sont abordés successivement: espace, temps, personnages, action dans la fête.

Selon les traditions, la noce s'est déroulée soit près du lac Tritonis en Libye, soit dans l'île de Samothrace ou encore à Thèbes. Chaque lieu possède des prérogatives mythiques qui les caractérisent de manière univoque : le lac et l'île sont proches du ciel, aux marges du monde, Thèbes est également céleste, comme le montre la conformation de sa muraille aux sept portes. Mais tandis que les conditions de la vie des Bienheureux se poursuivent dans l'île et au bord du lac, dans la cité fondée par Kadmos, le temps des hommes succède à celui des Bienheureux au terme de la cérémonie du mariage.

Le héros, par son mariage, instaure une harmonie nouvelle, un lien particulier entre les hommes et les dieux, lien qui fonde le cosmos grec (le fait que Kadmos appartient à un temps où ce cosmos n'est pas encore constitué justifierait, d'après l'A., son origine proche-orientale : il ne peut venir que d'un autre espace). Quant à Harmonie, son rôle correspond au champ sémantique recouvert par son nom : elle est l'harmonie qui unit deux mondes désormais inexorablement différents. Au cours des noces sont posés des actes séparateurs (don du blé par Déméter et définition des domaines humain et divin dans l'exercice de la 